\title{
IMPACT OF HEALTH EDUCATION ON KNOWLEDGE ON CHILD SEXUAL ABUSE AMONG TEACHERS IN TWIN CITIES OF PAKISTAN
}

\author{
Zahid Naeem ${ }^{1}$, Saba Savul', Umme Kulsoom Khattak' ${ }^{1}$, Kholood Janjua ${ }^{1}$ \\ Shifa college of Medicine Islamabad \\ Correspondence: Zahid Naeem, zahid.scm@stmu.edu.pk
}

\begin{abstract}
Background: Child sexual abuse is a critical and neglected public health issue in Pakistan. The objective of this study was to evaluate the impact of a health education intervention on knowledge of child sexual abuse among school teachers of Islamabad and Rawalpindi

Methods: This interventional community trial was conducted in eight private schools in Islamabad and Rawalpindi from March to June 2018. Schools were randomly selected and the study participants consisted of female teachers above 20 years of age. Teachers were given knowledge regarding child sexual abuse by means of comprehensive presentations, videos and distribution of written educational materials. Data were collected by a pre-tested selfdesigned questionnaire which was completed by the study participants before and after the health education intervention. Data analysis was done using SPSS version 23. Paired t-test was used to determine the mean difference and McNemar's test was used for pairwise comparison of knowledge before and after the intervention.

Results: The mean age of teachers was $27.63( \pm 5.16)$ years and the average time spent in teaching profession was 5.44 ( \pm 3.58 years). The mean pre-workshop score was $10.06( \pm 2.65)$ and the mean post-workshop score was 18.35 $( \pm 1.28)$. The mean difference between these two scores was statistically significant $(p<0.001)$. The total percentage of correct answers was $50.2 \%$ before the intervention and $90.8 \%$ after the intervention ( $p$-value <0.001). Conclusion: The health education intervention dispelled various myths and was successful in improving knowledge and awareness regarding child sexual abuse among school teachers in twin cities of Pakistan.
\end{abstract}

Keywords: Child sexual abuse, health education, teachers, schools, Pakistan

\section{Introduction}

Child sexual abuse (CSA) can be defined as a form of child abuse in which an adult, older child or family member uses a child for sexual activity or stimulation.(1) CSA involves both physical and non-physical contact such as forced exposure to pornography, filming or photographing a child in a sexual manner, deliberately exposing genitalia to a child, watching a child undress or use the bathroom and asking a child inappropriate questions about relationships and sexual behavior $(1,2)$. The commonly stipulated risk factors include poverty, absent or single parenting, history of past abuse, domestic violence, adopted or stepchildren, poor family bonding, parental mental illness and substance abuse. $(3,4)$ CSA leads to a wide array of short and long term impacts on the victim. Children who sexually abused can exhibit regressive behaviors such as bedwetting, inappropriate sexual activity, personality changes, withdrawal behavior,sleep disturbances and eating problems.(5) CSA is also associated with a wide range of mental disorders in later life including post traumatic stress disorder (PTSD), anxiety disorders, depression, alcohol and drug abuse, and suicidal behavior.(6) Being a victim of CSA increases the risk of high-risk sexual behaviors and sexual abuse in later life.(7)

CSA is prevalent globally and occurs across all countries, races, cultures and socio-economic classes. It can happen anywhere, e.g. in homes, schools, playgrounds, etc. Children of all ages are vulnerable to CSA. Although girls are most commonly victims of sexual abuse, both boys and girls are susceptible to CSA. $(6,8)$ In majority of cases, the perpetrator is known to the victim.9 A significant proportion of cases of CSA remain undisclosed and unidentified due to various factors such as guilt, shame, confusion, fear of being disbelieved, fear of the abuser, social and cultural barriers and religious beliefs.(9)

CSA constitutes a significant public health problem in Pakistan. There is no legal definition of child sexual abuse and accompanying legal action against perpetrators. There is very limited research related to CSA in Pakistan. According to a national nongovernmental organisation (NGO) Sahil, 4139 CSA 
cases of CSA were reported in 2016 and about 11 children are abused per day.(10) A large number of cases remain unreported. Cultural and religious sensitivities create a silent and hidden aura about CSA in the country.

Children spend a significant amount of time in educational institutes and have the greatest amount of contact with teachers apart from their families. Imparting teachers with knowledge and training about CSA can play a vital role in identifying, responding and preventing CSA.(11) A significant body of research has shown that education based school programs are effective in the protection against CSA.(12) Studies have also demonstrated that training of teachers is beneficial in this regard $(13,14)$.

The aim of our study was to assess the impact of a health education intervention among school teachers of Islamabad and Rawalpindi to help in identification and prevention of CSA. To the best of our knowledge, no such study has been conducted before in Pakistan.

\section{Methodology}

This interventional study was conducted in primary schoolsof Islamabad and Rawalpindi from March to June 2018. Eight schools in private sector were randomly selected and the sample consisted of teachers above twenty years of age in the selected schools who voluntarily agreed to take part in the study. Schools or teachers who refused to participate in the study were excluded. Only female teachers were selected for the study because in Pakistan male teachers at primary school level are in extreme minority. A sample size of 72 teachers was calculated using WHO sample size calculator considering the following parameters; confidence level as $5 \%$, test power as $90 \%$, mean CSA pre-score as $4.68(\mathrm{SD}=2.08)$ and mean post-score as $5.81(\mathrm{SD}=2.11) .(15)$

Ethical approval for the study was taken from the Institutional Review Board of Shifa International Hospital and approval was also sought from all participating schools in the study. Written informed consent was obtained from every study participant. A small scale pilot study involving $10 \%$ of the sample size was conducted in a primary school prior to the main study. The questionnaire was tested to ensure its reliability and was revised to make it easier to understand and answer. The study participants were given comprehensive knowledge regarding child sexual abuse by means of detailed presentations, though videos and distribution of written educational materials on child sexual abuse. Data was collected using a self-designed pre-tested questionnaire consisting of socio-demographic variables and 20 multiple choice questions to test changes in the knowledge and levels of awareness of study participants regarding child sexual abuse before and after the health education intervention. The questionnaires were filled in by the study participants under supervision of the research team. Data was entered and analyzed using SPSS version 23.
Frequency and percentage were computed for qualitative variables. Mean and standard deviation was calculated for quantitative variables. Participants who answered correctly were awarded "one" point and those who answered incorrectly or were unsure were given "zero" points. Paired t-test was applied to compare the mean score before and after the intervention. McNemar's test was used for pairwise comparison of correct answers between the pre-intervention and postintervention groups. P-values less than 0.05 were considered statistically significant.

\section{Results}

The mean age of teachers was $27.63 \pm 5.16$ years and the average time spent in teaching profession was $5.44 \pm$ 3.58 years. Only three $(4.2 \%)$ teachers had previously encountered a case of CSA at school. In this study, four $(5.6 \%)$ teachers had received previous training regarding child sexual abuse and they were excluded to prevent bias.

Table I: Socio-demographic profile of study participants

\begin{tabular}{|c|c|c|}
\hline Characteristic & Frequency & Percentage \\
\hline \multicolumn{3}{|l|}{ Marital status } \\
\hline Unmarried & 36 & 50.0 \\
\hline Married & 31 & 43.1 \\
\hline Divorced/separated/widowed & 2 & 2.8 \\
\hline Unknown & 3 & 4.2 \\
\hline \multicolumn{3}{|l|}{ Children } \\
\hline Yes & 26 & 36.1 \\
\hline No & 46 & 63.9 \\
\hline \multicolumn{3}{|l|}{ Educational Qualification } \\
\hline Diploma & 5 & 6.9 \\
\hline Bachelors & 29 & 40.3 \\
\hline Masters & 34 & 47.2 \\
\hline Other & 4 & 5.6 \\
\hline \multicolumn{3}{|l|}{ Class taught } \\
\hline One & 17 & 23.6 \\
\hline Two & 14 & 19.4 \\
\hline Three & 18 & 25.0 \\
\hline Four & 11 & 15.3 \\
\hline Five & 12 & 16.7 \\
\hline \multicolumn{3}{|l|}{ Years in teaching profession } \\
\hline $1-3$ & 31 & 43 \\
\hline $4-6$ & 11 & 15.2 \\
\hline $7-9$ & 18 & 25 \\
\hline $10-12$ & 12 & 16.6 \\
\hline
\end{tabular}

The mean pre-workshop score was $10.06( \pm 2.65)$ and the post-workshop score was $18.35( \pm 1.28)$. This difference was statistically significant $(p<0.001)$. There was no significant difference in pre-score with regards to marital status, number of children, grade taught, educational qualification and time spent in teaching profession. 
Table 2: Pairwise comparison regarding understanding of child sexual abuse $(n=72)$

\begin{tabular}{|c|c|c|c|}
\hline merslaining or & $\begin{array}{l}\text { Pre-intervention } \\
\text { correct answers }\end{array}$ & $\begin{array}{l}\text { Post-intervention } \\
\text { correct answers } \\
\text { N (\%) }\end{array}$ & $\begin{array}{c}\text { p- } \\
\text { values }\end{array}$ \\
\hline Child sexual abuse is rare in Pakistan & $33(45.8)$ & $68(94.4)$ & $<0.001$ \\
\hline $\begin{array}{l}\text { Children are more likely to be sexually abused by a } \\
\text { stranger }\end{array}$ & $27(37.5)$ & $68(94.4)$ & $<0.001$ \\
\hline Only female children can be sexually abused & $42(58.3)$ & $66(91.6)$ & $<0.001$ \\
\hline $\begin{array}{l}\text { Family members and close relatives cannot sexually } \\
\text { abuse a child }\end{array}$ & $40(55.5)$ & $65(90.2)$ & $<0.001$ \\
\hline Sexual abuse only consists of rape & $34(47.2)$ & $67(93.0)$ & $<0.001$ \\
\hline $\begin{array}{l}\text { Children being sexually abused are harmed and killed } \\
\text { in some cases }\end{array}$ & $51(70.8)$ & $68(94.4)$ & $<0.001$ \\
\hline Sexual abuser is always a male & $27(37.5)$ & $64(88.8)$ & $<0.001$ \\
\hline $\begin{array}{l}\text { Children can make up stories about sexual abuse to } \\
\text { gain sympathy and attention }\end{array}$ & $30(41.6)$ & $62(86.1)$ & $<0.001$ \\
\hline $\begin{array}{l}\text { Children who have been sexually abused show } \\
\text { psychological effects }\end{array}$ & $35(48.6)$ & $68(94.4)$ & $<0.001$ \\
\hline $\begin{array}{l}\text { Sexual comments and inappropriate touching are a } \\
\text { form of sexual abuse }\end{array}$ & $32(44.4)$ & $66(91.6)$ & $<0.001$ \\
\hline $\begin{array}{l}\text { Showing a child inappropriate videos and } \\
\text { photographs constitutes child abuse }\end{array}$ & $33(45.8)$ & $68(94.4)$ & $<0.001$ \\
\hline $\begin{array}{l}\text { Use of drugs is an aggravating factor in child sexual } \\
\text { abuse }\end{array}$ & $43(59.7)$ & $63(87.5)$ & $<0.001$ \\
\hline $\begin{array}{l}\text { Poverty and illiteracy are important root causes of } \\
\text { child sexual abuse }\end{array}$ & $51(70.8)$ & $55(76.3)$ & 0.454 \\
\hline $\begin{array}{l}\text { Most children who have been sexually abuse } \mathrm{d} \text { will } \\
\text { tell someone }\end{array}$ & $21(29.1)$ & $64(88.8)$ & $<0.001$ \\
\hline Children below 7 years cannot be sexually abused & $23(31.9)$ & $65(90.2)$ & $<0.001$ \\
\hline $\begin{array}{l}\text { If a child exhibits behavior/ performance problems at } \\
\text { school and is unwilling to participate in school and } \\
\text { social activities they could be a victim of sexual } \\
\text { abuse }\end{array}$ & $24(33.3)$ & $64(88.8)$ & $<0.001$ \\
\hline $\begin{array}{l}\text { Children should be taught about their body parts and } \\
\text { where they should or should not be touche d by } \\
\text { anyone }\end{array}$ & $46(63.8)$ & $70(97.2)$ & $<0.001$ \\
\hline $\begin{array}{l}\text { Any complaint made by a child regarding sexual } \\
\text { abuse should be reported to parents and school } \\
\text { authorities }\end{array}$ & $43(59.7)$ & $68(94.4)$ & $<0.001$ \\
\hline $\begin{array}{l}\text { Cases of child sexual abuse are underreported in } \\
\text { Pakistan }\end{array}$ & $28(38.8)$ & $63(87.5)$ & $<0.001$ \\
\hline $\begin{array}{l}\text { Good child-parent/caregiver relationship is necessary } \\
\text { to decrease the chances of sexual abuse }\end{array}$ & $60(83.3)$ & $66(91.6)$ & 0.109 \\
\hline
\end{tabular}

\section{Sexual abuser is always a male}

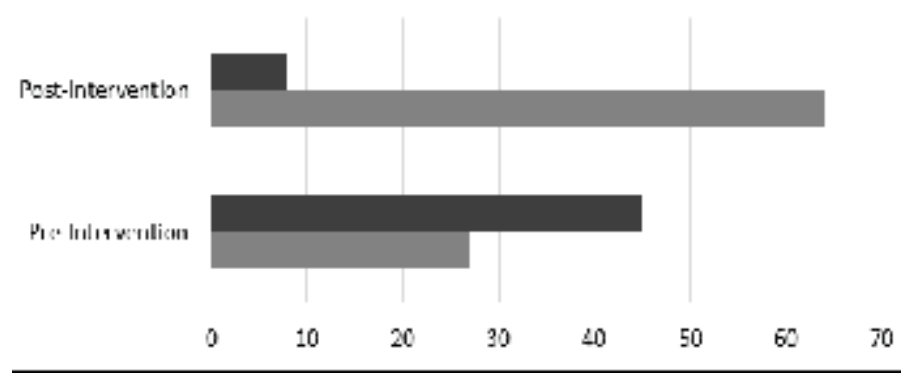

Children are more likely to be sexually abused by a stranger

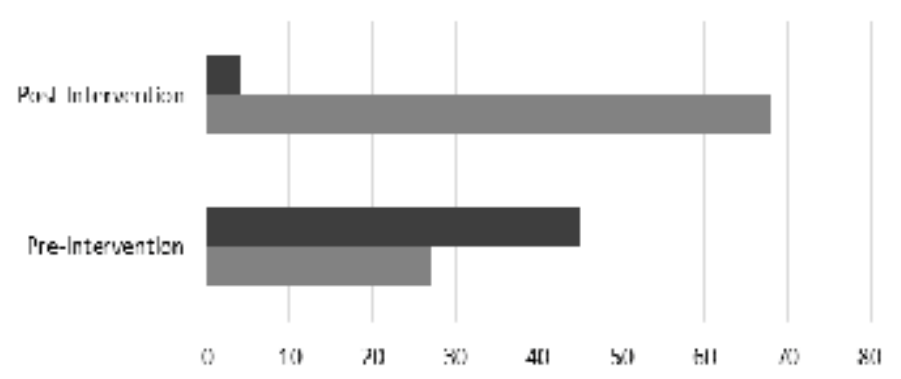

\section{Child Sexual Abuse is rare in Pakistan}

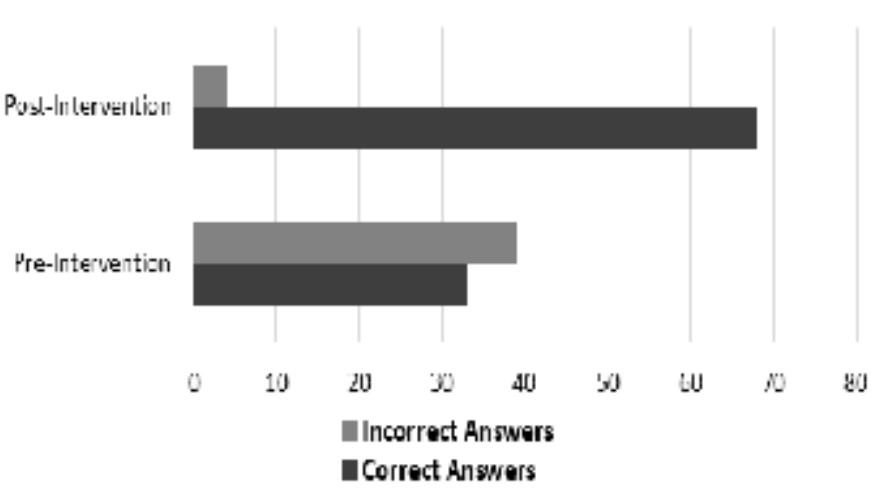

Figure I: Comparison of knowledge before and after the health intervention

\section{Discussion}

The study results reveal that there isa profound lack of knowledge regarding CSA among school teachers in twin cities of Pakistan.Our researchestablished that the difference between the mean pre and post intervention score was statistically significant highlighting the fact that the intervention was beneficial in increasing knowledge of CSA in school teachers.

The number of correct answers for most questions increased significantly after the health education intervention. Pre-intervention 23 (31.9\%) teachers discerned that children below seven years can be sexually abused, 27 (37.5\%) teachers thought that children were more likely to be sexually abused by a stranger and $42(58.3 \%)$ believed that only female children can be sexually abused. These results are similar to those of the Chinese study where only $38.2 \%$ teachers believed that preschool-aged children can be sexually abuse, $54.5 \%$ recognized that children are most oftensexually abused by familiar people and $65.1 \%$ understood that boys can also be sexually abused.15 Post intervention the numbers improved significantly with $65(90.2 \%)$ teachers cognizing that children of any age can be sexually abused, 68 (94.4\%) affirming that children were more likely to be sexually abused by someone known to them and 66 (91.6\%) acknowledging that both male and female children can be victims of CSA.

Prior to the intervention, $33(45.8 \%)$ participants assumed that CSA is rare in Pakistan, which increased to $68(94.4 \%)$ after the intervention. Similarly, before the intervention, $28(38.8 \%)$ teachers believed that cases of CSA were unreported in Pakistan with numbers rising to $63(87.5 \%)$ after the intervention. The fact that children who are sexually abused can be harmed and killed was recognized by $51(70.8 \%)$ and $68(94.4 \%)$ teachers, pre and post intervention respectively, a difference of 17 $(23.6 \%)$ teachers although not vast but nonetheless 
statistically significant.

A mere 24 (33.3\%) teachers were able to recognize that a child exhibiting behavior or performance problems at school and unwilling to participate in school and social activities could be a victim of sexual abuse. This finding is in agreement with that of another study where a majority of teachers $(90.7 \%)$ had problems identifying child sexual abuse.(16) Post intervention, 64 (88.8\%) teachers were able to comprehend that behavioral and social issues could be indicative of underlying CSA. Before the intervention, 21 (29.1\%) teachers believed that victims of sexual abuse will tell someone whereas post-intervention $64(88.8 \%)$ teachers realized that children are highly likely not to disclose sexual abuse.

Post-intervention 68 (94.4\%) teachers firmly believed that any complaint made by a child regarding sexual abuse should be reported to parents and school authorities as compared to $43(59.7 \%)$ prior to the intervention. This resonates with the results of an Australian study where majority of teachers were equivocal regarding reporting of CSA citing lack of proper training and intervention courses in this regard.16 A crucial point underscored by our study was that children should be given awareness regarding their body parts and where they can be touched which was affirmed by $70(97.2 \%)$ teachers after the educational intervention.

In our study, 42 (58.4\%) teachers thought that children can make up stories about sexual abuse to gain sympathy and attention. This in sharp contrast to the results of the Spanish study where $80.7 \%$ teachers correctly regarded this belief as false.(17) Postintervention only $10(13.9 \%)$ teachers held on to this misconception. Regarding the gender of the abuser, 45 $(62.5 \%)$ teachers were of the view that it was a male comparable to beliefs of teachers in the Spanish study(18) whereas the reality is that females can be abusers too.(9)

The study results divulge that all dimensions of child sexual abuse were not fathomed by teachers. Only 34 $(47.2 \%)$ teachers understood that sexual abuse does not only encompass rape, $32(44.4 \%)$ realized that sexual comments and inappropriate touching are a form of sexual abuse and $33(45.8 \%)$ comprehended that exposing a child to inappropriate videos and photographs constitutes child sexual abuse. Our health intervention improved knowledge in all these areas with over $66(90 \%)$ teachers scoring correctly postintervention.

Only two questions did not show a statistically significant difference, i.e. "poverty and illiteracy are important root causes of CSA" and "good child-parent/caregiver relationship is necessary to decrease the chances of sexual abuse". It is postulated that participants already have prior awareness regarding these facts.

Since the study was limited to primary school teachers, the results may not be reflective of the views and knowledge of teachers in higher educational institutes in
Pakistan. Future research should target faculty of secondary and high schools in Pakistan.

\section{Conclusion}

This study disclosed and eradicated multiple erroneous views of teachers regarding child sexual abuse and established that the health education intervention was profoundly successful in increasing awareness and knowledge of CSA among school teachers in the twin cities of Pakistan. The study underscores a pressing need to develop appropriate CSA prevention training programs for school teachers in Pakistan. This can be achieved through several ways, including introduction of mandatory courses in curriculum for trainee teachers as well as educational seminars and workshops for teachers who are already working. 18 This can lead to the identification and protection of a sizable number of abused children in the country.

\section{References}

1. Greijer S, Doek J. Terminology Guidelines for the Protection of Children from Sexual Exploitation and Sexual Abuse [online] 2016 [cited 27 June 2018] Available from URL: https://www.unicef. org/protection/files/Terminology_guidelines_39 6922-E.pdf

2. Leeb RT, Paulozzi L, Melanson C, Simon T, Arias I. Child Maltreatment Surveillance: Uniform Definitions for Public Health and Recommended Data Elements [online] 2008 [cited 27 June 2018] Available from URL: https://www.cdc.gov/ violenceprevention/pdf/CM_Surveillance-a.pdf

3. Whitaker DJ, Le B, Hanson RK, Baker CK, Pam $M M$, Ryan $G$, et al. Risk factors for the perpetration of child sexual abuse: A review and meta-analysis. Child Abuse Negl. 2008; 32(5): 529-48. doi: 10.1016/j.chiabu.2007.08.005.

4. World Health Organization. Guidelines for medico-legal care for victims of sexual violence [online] 2003 [cited 27 June 2018] Available from URL: http://apps.who.int/iris/bitstream/ 10665/42788/1/924154628X.pdf

5. Parents Protect! Child Sexual Abuse Warning signs [online] 2018 [cited 2 July 2018] Available from URL: https://www. parentsprotect. co.uk/warning_signs.htm

6. Pérez-Fuentes G, Olfson M, Villegas L, Morcillo C, Wang S, Blanco C. Prevalence and correlates of child sexual abuse: a national study. Compr Psychiatry. 2013; 54(1): 16-27. doi: 10.1016/j.comppsych.2012.05.010

7. Noll JG, Trickett PK, Putnam FW. A Prospective Investigation of the Impact of Childhood Sexual Abuse on the Development of Sexuality. J Consult Clin Psychol. 2003; 71(3): 575-586

8. Dube SR, Anda RF, Whitfield CL, Brown DW, Felitti VJ, Dong $M$, et al. Long-term consequences of childhood sexual abuse by gender of victim. Am J Prev Med. 2005; 28(5): 430-438 
9. Murray LK, Nguyen A, Cohen JA. Child Sexual Abuse. Child Adolesc Psychiatr Clin N Am. 2014; 23(2): 321-337. doi: 10.1016/j.chc.2014.01.003

10. Sahil. Cruel Numbers. [online] 2018 [cited 2 July 2018] Available from URL: http://sahil.org/cruelnumbers/

11. Scholes L, Jones C, Stieler-Hunt C, Rolfe B, Pozzebon K. The Teachers' Role in Child Sexual Abuse Prevention Programs: Implications for Teacher Education. Aust J Teach Educ. 2012; 37(11): 104-131

12. Walsh K, Zwi K, Woolfenden S, Shlonsky A. School-based education programmes for the prevention of child sexual abuse. Cochrane Database Syst Rev. 2015; 4: Cd004380

13. Kleemeier C, Webb C, Hazzard A, Pohl J. Child sexual abuse prevention: evaluation of a teacher training model. Child Abuse Negl. 1988; 12(4): $555-61$

14. Randolph MK, Gold CA. Child sexual abuse prevention: Evaluation of a teacher training program. Sch Psychol Rev. 1994; 23(3): 485495

15. Zhang W, Chen J, Liu F. Preventing Child Sexual Abuse Early: Preschool Teachers' Knowledge, Attitudes, and Their Training Education in China. SAGE Open. 2015; 5(1): 1-8. doi: org/10.1177/ 2158244015571187

16. Goldman JD. Grimbeek P. Preservice teachers' sources of information on mandatory reporting of child sexual abuse. J Child Sex Abus. 2015; 24(3): 238-58. doi: 10.1080/10538712. 2015.1009607.

17. Márquez-Flores MM, Márquez-Hernández VV. Granados-Gámez G. Teachers' Knowledge and Beliefs About Child Sexual Abuse. J Child Sex Abus. 2016; 25(5): 538-555. doi: 10.1080/ 10538712.2016.1189474.

18. Sinanan, Allison N. Bridging the Gap of Teacher Education about Child Abuse. Educ Found. 2011; 25(3-4): 59-73. 